\title{
The Incrementality of Mayan Kaqchikel Phonological Encoding: Right or Leftwards?
}

\author{
Katsuo Tamaoka1, Kyoko Hayakawa1, Michael Patrick Mansbridge1, \\ Maria Eduardovna Bulaeva1, Kexin Xiong1, Masatoshi Koizumi², Kuniya Nasukawa3 \\ ${ }^{1}$ Graduate School of Languages and Cultures, Nagoya University, Nagoya, Japan \\ ${ }^{2}$ Graduate School of Arts and Letters, Tohoku University, Sendai, Japan \\ ${ }^{3}$ Graduate School of English Language and Literature, Tohoku Gakuin University, Sendai, Japan \\ Email: ktamaoka@lang.nagoya-u.ac.jp, hayakawa@lang.nagoya-u.ac.jp, michaelp.mansbridge@gmail.com, \\ mashabyaka@gmail.com, xiongkexindawai@yahoo.co.jp, koizumi@sal.tohoku.ac.jp, \\ nasukawa@mail.tohoku-gakuin.ac.jp
}

Received 15 March 2015; accepted 11 April 2015; published 15 April 2015

Copyright (C) 2015 by authors and Scientific Research Publishing Inc.

This work is licensed under the Creative Commons Attribution International License (CC BY). http://creativecommons.org/licenses/by/4.0/

(c) (i) Open Access

\begin{abstract}
Nasukawa, Yasugi and Koizumi (2013) propose that the dependency structure and stress assignment patterns in Kaqchikel are reversed compared to Indo-European languages. Following this argument, words in Kaqchikel are expected to be phonologically processed in a right-to-left incremental fashion, whereas the majority of languages process words left-to-right. Two experiments were conducted on native Kaqchikel speakers with high Spanish proficiency. Experiment 1 (word production) asked participants to produce as many words as possible containing a specific consonant in Kaqchikel and Spanish. The results showed that 1) participants generated more words in Spanish than in Kaqchikel; 2) most words were generated with the given consonants at the beginning of the word and 3 ) the fewest in the final position. Experiment 2 (phoneme monitoring) required participants to determine in Kaqchikel and Spanish whether a certain phoneme appeared in the name of an object pictured. Target phonemes were included as sounds in either initial (/kär/“fish"), ending (/chak/"grain") or neutral (no/k/sound, /q'aq'/fire”) conditions. Both Kaqchikel and Spanish displayed a similar pattern: pictures with the target phoneme in the initial position were always detected faster than those in the ending position, in both languages. Consequently, despite the claim by Nasukawa et al. (2013), the two experiments in the present study provided no evidence for the right-to-left phonological encoding in Kaqchikel; instead, both languages seemed to display the same left-to-right pattern.
\end{abstract}

\section{Keywords}

Incrementality, Phonological Encoding, Phoneme Monitoring, Mayan Kaqchikel, Spanish, Bilingual

How to cite this paper: Tamaoka, K., Hayakawa, K., Mansbridge, M. P., Bulaeva, M. E., Xiong, K. X., Koizumi, M., \& Nasukawa, K. (2015). The Incrementality of Mayan Kaqchikel Phonological Encoding: Right or Leftwards. Open Journal of Modern Linguistics, 5, 135-146. http://dx.doi.org/10.4236/ojml.2015.52012 


\section{Introduction}

In phonology, it is assumed that CV (consonant-vowel) is the most basic type of syllable. CV is the only syllable type which appears in all languages, and in addition, emerges at the earliest stages of acquisition (e.g. “mama”). The distribution of $\mathrm{C}$ and $\mathrm{V}$ suggests that a dependency relation exists between the two, where the presence of $\mathrm{C}$ is dependent on $\mathrm{V}$. This is supported by the fact that a single $\mathrm{C}$ cannot form a free morpheme, but rather, must be followed by V, e.g. /ti:/ "tea”, /tu:/ "two", yet not */t/, */p/. On the other hand, a single V can form a free morpheme, e.g. /aI/ "I", /rə/ “ear”. The obligatory presence of V in a syllable is reflected in its status as the nucleus or head of the syllable. By contrast, the optional C occupies a non-head (dependent) position.

In words with more than one syllable, a dependency relation also exists between syllables. Consider the sequence $\left(\mathrm{C}_{1} \mathrm{~V}_{1}\right)_{\sigma}\left(\mathrm{C}_{2} \mathrm{~V}_{2}\right)_{\sigma}$ in the English words /'p $\Lambda \mathrm{pi}$ / “puppy” and /'siti/ “city”, where stops are aspirated before a stressed vowel. In English, native (i.e. Germanic-origin) words tend to be stressed on $\mathrm{V}_{1}$, giving the first syllable greater salience or prominence than the second. This salience affects both $V_{1}$ and $C_{1}$ : the vowel in $V_{1}$ is stressed, while the consonant in $\mathrm{C}_{1}$ is aspirated, e.g. ['p ${ }^{\mathrm{h}} \Lambda \mathrm{pi}$ ] (cf. no aspiration on the stop preceding the unstressed $\mathrm{V}_{2}$ ). Traditionally $\mathrm{C}_{1}$ (aspirated stop) and $\mathrm{V}_{1}$ (stressed vowel) are treated as strong positions while $\mathrm{C}_{2}$ (non-aspirated stop) and $\mathrm{V}_{2}$ (unstressed vowel) are weak. Strong-weak relations account for other phonological phenomena as well, such as consonant lenition and vowel reduction, both being associated with weak positions.

In representational theories such as Dependency Phonology (Anderson \& Ewen, 1987; Van der Hulst, 1995) and Government Phonology (Harris 1994, 1997; Nasukawa, 2011; Kaye, 1990; Kaye, Lowenstamm, \& Vergnaud, 1990), strong-weak is built into phonological structure, with strong positions serving as the head of their domain. So, in [' $\mathrm{p}^{\mathrm{h}} \Lambda \mathrm{pi}$ ] the $\mathrm{C}_{1} \mathrm{~V}_{1}$ sequence is the head of the word domain, with $\mathrm{C}_{2} \mathrm{~V}_{2}$ as its dependent. By combining this with the head-dependent relation between $\mathrm{C}$ and $\mathrm{V}$ within each syllable, we get the following dependency path for a $\left(\mathrm{C}_{1} \mathrm{~V}_{1}\right)_{\sigma}\left(\mathrm{C}_{2} \mathrm{~V}_{2}\right)_{\sigma}$ word:

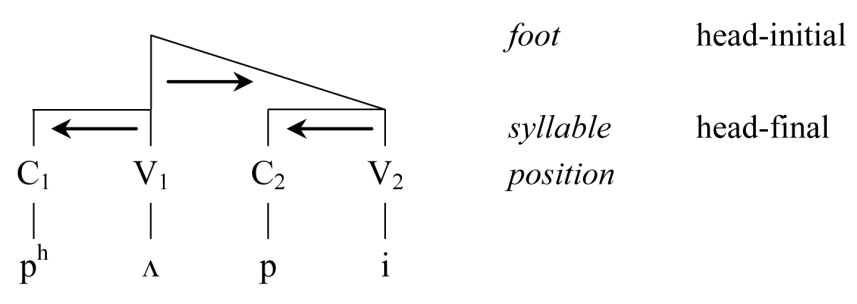

(1) shows the prosodic structure of the English word puppy (where $\rightarrow$ expresses a dependency relation, e.g. “ $\alpha \rightarrow \beta$ " indicates that and " $\alpha$ is dominant over $\beta$ " and " $\beta$ is dependent on $\alpha$ "). The four positions form two syllable domains, $C_{1} V_{1}$ and $C_{2} V_{2}$, in which $C$ is dependent on $V$ (see above). The two syllables then form another dependency relation to create a foot. In this case $C_{1} V_{1}$ is the head of the foot domain and, because it is not dominated by anything else, $\mathrm{V}_{1}$ is the head of the entire word domain.

Even in words such as [p $\mathbf{p}^{\mathbf{h}}$ It] "pit" and [ $\mathrm{t}^{\mathrm{h}} \mathrm{Ip}$ ] "tip", which have $\mathrm{C}_{1} \mathrm{~V}_{1} \mathrm{C}_{2}$ rather than $\mathrm{C}_{1} \mathrm{~V}_{1} \mathrm{C}_{2} \mathrm{~V}_{2}$ (i.e. they appear to lack a final $\mathrm{V}_{2}$ ), we find the same distribution of $\mathrm{C}$ and $\mathrm{V}: \mathrm{C}_{1}$ is strong (and aspirated) while $\mathrm{C}_{2}$ is not. This

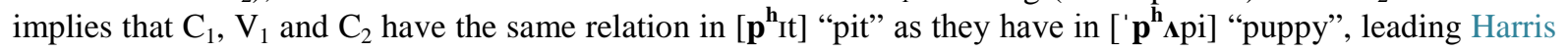
\& Gussmann $(1998,2002)$ to claim that $\mathrm{C}_{1} \mathrm{~V}_{1} \mathrm{C}_{2}$ has the same structure as (1). This is shown in (2) below.

(2)

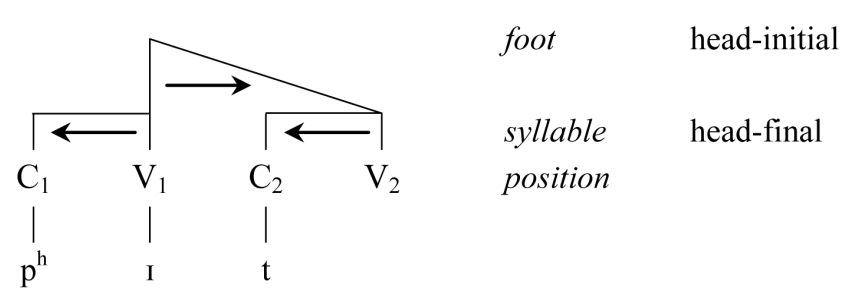

If $\mathrm{C}_{1} \mathrm{~V}_{1} \mathrm{C}_{2}$ and $\mathrm{C}_{1} \mathrm{~V}_{1} \mathrm{C}_{2} \mathrm{~V}_{2}$ have the same structure, then in both cases $\mathrm{C}_{2}$ must be an onset (i.e. the onset of the second syllable). Harris \& Gussmann (1998, 2002) provide several arguments to support this view that wordfinal consonants in English are indeed onsets-and moreover, that these onsets are followed by an empty nuc- 
leus (i.e. a position with no vowel). For instance, they refer to syllable typology, word stress and vowel length as evidence against the traditional practice of syllabifying a word-final $C$ as a coda. They contend that a word-final consonant cannot be a coda because it does not display the typical properties of a coda. The same applies in other languages such as French (Charette, 1991), Japanese (Nasukawa, 2004), Icelandic and Polish (Harris \& Gussmann, 1998, 2002), where it has been argued that a lexical domain must end in an onset-nucleus sequence, and never in a coda. On this basis, the difference between languages which allow word-final consonants (e.g. English) and those which do not (e.g. Japanese) comes down to a choice between allowing a final nucleus to be empty or not. This approach has enriched our understanding of a number of phonological phenomena (Nasukawa, 1998, 2004).

\section{Identifying the Syllable Structure of Kaqchikel}

In the Mayan language Kaqchikel, as in English, stops are aspirated in predictable environments. However, the distribution of aspiration and stress assignment in Kaqchikel is the exact reverse of the English pattern: aspiration occurs only in syllable- and word-final stops, and stress is assigned only to syllable- and word-final Vs (e.g., [tóp $\left.{ }^{\mathbf{h}}\right]$ "crab", [tát'] "father"). Consequently, it is the domain-final position which seems to show salience or prominence, while domain-initial position is relatively weak and displays the effects of lenition (e.g., [q"aq”] > ['aq'] "fire”). To account for this, Nasukawa, Yasugi \& Koizumi (2013) claim that Kaqchikel has a marked syllable structure in which $C_{1}$ is a weak position while the sequence $V_{2} C_{2}$ (a stressed $V_{2}$ followed by aspirated $C_{2}$ ) is strong. In terms of head-dependency, $V_{2}$ is the head of the syllable and $C_{2}$ is dependent on $V_{2}$. This makes $C_{1}$ the most embedded part of the whole structure, as shown in (3).

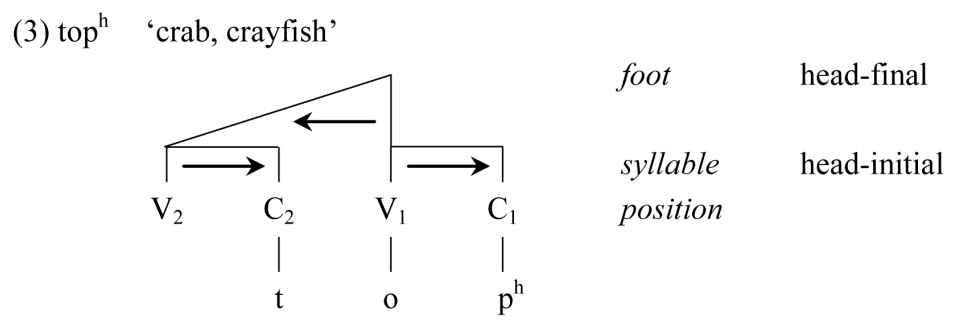

In the Kaqchikel word top $p^{h}$ in (3), four positions are organized into two syllable-sized units, $\mathrm{V}_{2} \mathrm{C}_{2}$ and $\mathrm{V}_{1} \mathrm{C}_{1}$. As before, within each syllable $\mathrm{C}$ is dependent on $\mathrm{V}$. And again, the two syllables form another dependency relation to create a foot, but in the case of Kaqchikel the right-hand syllable is the head of the foot domain.

If this marked structure is indeed valid for Kaqchikel, then we are forced to reexamine the view that syllables universally consist of head-final CV sequences. Instead, we may conjecture that the directionality of head-dependency relations is parametric even at the syllable level.

\section{Psychological Reality of the Linguistic Argument: The Levelt et al. (1999) Model}

It is important to evaluate how the aforementioned linguistic argument holds up in psychological reality. One way to assess this is to evaluate it against established models in the psycholinguistic literature; particularly those dealing with language production processes. Although there are other models out there, we opted for the well-known word-production model by Levelt, Roelofs \& Meyer (1999) as it makes specific claims concerning the construction of phonological syllables of words. The model describes how language production takes place and distinguishes several important steps (see Figure 1 for a graphical overview).

First of all, at the conceptual level, contents of the utterance related to the communicative intent will become activated. For instance, if one has the intention to convey the notion of a "puppy", first the appropriate concept, PUPPY(X) (i.e. semantics of "puppy") will be activated. Subsequently, the activated concept will spread (some of) its activation to its lexical-syntactic representation (also known as a "lemma") containing the word's lexical-syntactic information (e.g. word class information, inflections, plurality, gender information in particular languages, etc.). The time it takes to select the target lexical-syntactic representation depends on the number of co-activated lexical-syntactic nodes (and their respective activation strengths) that is presumed to compete for selection. According to the model, one lexical-syntactic representation is eventually selected (i.e. "wins the competition") and is processed through to the subsequent word form encoding level (but see Roelofs, 2008 for a "weakly cascading” 


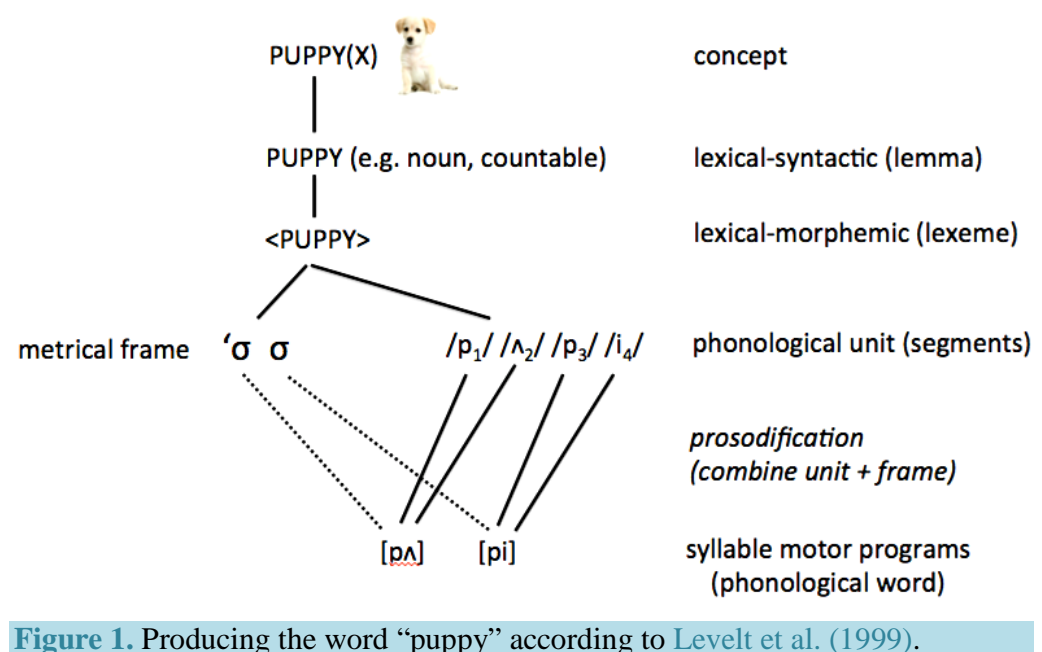

alternative). First of all, at the level of phonological word-form encoding, the morphemes (e.g. $<$ PUPPY $>$ ) that constitute the utterance will be retrieved from the mental lexicon. Subsequently the metrical information and units making up these morphemes will be processed. In the case of English, this involves the left-to-right incremental clustering of phonological segments into a syllabic pattern (e.g. $/ \mathrm{p} / / \mathrm{\Lambda} / / \mathrm{p} /$ and $/ \mathrm{i} /$ ). Metrical encoding at this level includes determining the number of syllables and the stress (English/Dutch), tone (Chinese) or pitch accent (Japanese) placement in the word (Roelofs, 2015). The final part of the speech production process is concerned with how to turn the phonologically specified words into motor instructions that can be produced by the articulatory system and ultimately will allow for overt speech.

\section{How Does Kaqchikel Phonological Encoding Fit into the Levelt et al. (1999) Model?}

The argument Nasukawa et al. (2013) make, proposing the exact reverse dependency structure and stress assignment pattern for Kaqchikel, allows for speculation whether this assertion might also psychologically manifest itself in the construction of phonological words in Kaqchikel. That is to say, for English/Dutch the Levelt et al. (1999) model clearly states that the phonological word is constructed in a left-to-right incremental fashion. Most of the evidence for this claim comes from the implicit priming paradigm. This paradigm (originally conducted in Dutch) is composed of two stages, a learning and a test stage. In the learning stage, participants are required to remember a small number of word pairs (also called prompt-response pairs, e.g. tovenaar [magician] -> heks [witch]). In the following test stage, a prompt word (tovenaar [magician]) is presented on the screen and participants have to produce the appropriate response word (heks [witch]) as fast and accurately as possible. The prompt-response pairs are spread in such a way to create two group types: homogenous groups and heterogeneous groups. In the homogenous group, all of the response words share the initial phoneme (e.g., hut, heks, hiel, hoop, haard [hut, witch, heel, heap, stove]), while in the heterogeneous group, no response word shares the initial phoneme (e.g., hut, dans, klip, pool, storm [hut, dance, cliff, pole, storm]). In languages such as Dutch and English, response words are produced significantly faster when response words minimally share the initial phoneme than when they do not (Meyer, 1990, 1991; Roelofs, 1996). However, there is no facilitation when they share end-related phonology (e.g. boek, doek, snoek, hoek, vloek [book, canvas, pike, corner, curse]) attesting to the left-to-right incremental nature of the encoding process. The facilitation effect suggests anticipatory preparation of the shared word-form, which facilitates naming in homogeneous blocks. This paradigm has been applied to other languages such as Chinese (Chen, Chen, \& Dell, 2002) and Japanese (Kureta, Fushimi, \& Tatsumi, 2006) and is one of the workhorses to investigate phonological encoding processes.

As stated before, the Levelt et al. (1999) model assumes left-to-right incremental phonological encoding, however, according to the arguments by Nasukawa et al. (2013) it might be that the exact opposite pattern is present in Kaqchikel. In other words, the Kaqchikel word /top/ (“crab, crayfish”) may be incrementally constructed in a right-to-left fashion (i.e. first accessing the aspirated /p/ then /o/ then /t/). Obviously, the word itself is not pronounced in a reversed pattern, but the possibility exists that the underlying phonological word encod- 
ing process shows reverse right-to-left incrementality.

This paper presents two psycholinguistic experiments attempting to reveal the underlying mechanisms responsible for the generation of Kaqchikel phonology. Since we expected a sizeable portion of our participants for the experiments (Mayan people living near Antigua, Guatemala) to be illiterate (at least in Kaqchikel) to varying degrees, it was not deemed feasible to run a classic implicit priming study (which involves reading). Therefore, we performed a word-generation experiment and a phoneme monitoring experiment.

\section{Experiments}

\subsection{Experiment One: Word Generation in Kaqchikel and Spanish}

Experiment one was performed in Kaqchikel as well as in Spanish, as Spanish is the official language of Guatemala. The task was quite simple, participants were given one particular consonant at a time and their task was to produce as many words as they could containing this consonant (any position in the word was allowed) in the time-span of one minute (per consonant). The rationale behind this experiment was to simply assess whether the number of words being generated in Kaqchikel with the provided consonant at the end position is higher than the more common preference (higher count) for the initial position. If right-to-left incrementality takes place in the construction of Kaqchikel phonology, the frequency of words with the consonant in final position should be relatively high. This test also allows for a comparison between Kaqchikel and Spanish and additionally serves as an indicator regarding the relative proficiency of the participants in Kaqchikel and Spanish by assessing the total word counts.

Participants. In all experiments mentioned in this paper, we tested the same initial group of 72 Guatemalan citizens (31 males and 41 females; mean age $\pm \mathrm{SD}=31.96$ years \pm 9.62 ) from Mayan descent. All participants were recruited by the Comunidad Lingüística Kaqchikel in Antigua, Guatemala, and (recruiting requirement) were considered to be native speakers of Kaqchikel. All gave written, informed consent concerning their participation in the experiments.

Stimuli. We selected the consonants /ch/, /k'/, /m/, /p/, /q'/ for Kaqchikel and /d/, /l/, /n/, /r/, /s/ for Spanish.

Procedure. Participants were provided with a particular consonant (random order) by the experimenter. Instructions were provided either in Kaqchikel or Spanish depending on the response language. For each session participants had to generate words with the particular consonant; a break was administered after which another consonant was verbally given to the participant and the task was repeated ( 5 consonants per language; 1 minute per consonant; lasting roughly 8 - 10 minutes including a practice consonant). Participants were instructed that any position would be okay (beginning, ending or middle) as long as the word had that particular consonant in it. The participants' responses were recorded during the whole experiment and a native speaker transcribed the generated words post-hoc for Kaqchikel and Spanish for the subsequent analysis.

Results. We found that participants were able to generate approximately 2.6 times more words in Spanish than in Kaqchikel. Additionally, in Kaqchikel it seems to be that more words starting with a particular given consonant are generated compared to the other conditions, $\chi^{2}(8)=98.15, p<.001$. A similar pattern was found for Spanish, $\chi^{2}(8)=313.49, p<.001$. See Table 1 for an overview of the counts (combined for all participants).

Discussion. It seems that participants are more readily able to generate words in Spanish than in Kaqchikel $(N=$ 5587 vs. $N=2144$ ). Importantly, we did not find any evidence for an increased number of words ending with the given consonants in Kaqchikel. In fact, the pattern of results seems to be quite similar between both languages. Most words are generated with the given consonants at the beginning of the word and the fewest words are generated with consonants in the final position. Additionally, the middle position generated more words compared to the final position. In all, these results do not hint at a right-to-left incrementality for Kaqchikel phonological encoding. However, one particular confound may be that there is no lexical corpus available for Mayan Kaqchikel. It may be that there are fewer words available with the provided consonants at the end position. For instance, we observed relatively more words ending with /q'/ compared to the other consonants we used $(/ \mathrm{ch} /, / \mathrm{k} /, / \mathrm{m} /$ and $/ \mathrm{p} /$ ). However, even assuming this (summed) number is equally distributed amongst participants, this means that (perhaps except for $/ q^{\prime} /$ ) a significant part of the participants did not even utter a single word ending with the given consonants in Kaqchikel. This hints strongly towards the notion that these participants typically had the onset in mind for Kaqchikel (and Spanish) when faced with the task of coming up with words containing particular consonants. 
Table 1. Results experiment 1 (word generation task).

\begin{tabular}{|c|c|c|c|c|c|}
\hline \multicolumn{3}{|c|}{ Kaqchikel } & \multicolumn{3}{|c|}{ Spanish } \\
\hline Sound & Position & Frequency & Sound & Position & Frequency \\
\hline \multirow{3}{*}{$/ \mathrm{ch} /$} & Initial & 293 & \multirow{3}{*}{$/ \mathrm{d} /$} & Initial & 731 \\
\hline & Medial & 90 & & Medial & 371 \\
\hline & Final & 50 & & Final & 51 \\
\hline \multirow{3}{*}{$/ \mathrm{k}^{\prime} /$} & Initial & 287 & \multirow{3}{*}{$/ 1 /$} & Initial & 742 \\
\hline & Medial & 61 & & Medial & 224 \\
\hline & Final & 38 & & Final & 62 \\
\hline \multirow{3}{*}{$/ \mathrm{m} /$} & Initial & 295 & \multirow{3}{*}{$/ \mathrm{n} /$} & Initial & 664 \\
\hline & Medial & 98 & & Medial & 381 \\
\hline & Final & 55 & & Final & 117 \\
\hline \multirow{3}{*}{$/ \mathrm{p} /$} & Initial & 287 & \multirow{3}{*}{$/ \mathrm{r} /$} & Initial & 731 \\
\hline & Medial & 36 & & Medial & 371 \\
\hline & Final & 11 & & Final & 256 \\
\hline \multirow{3}{*}{$/ q^{\prime} /$} & Initial & 314 & \multirow{3}{*}{$/ \mathrm{s} /$} & Initial & 659 \\
\hline & Medial & 118 & & Medial & 201 \\
\hline & Final & 111 & & Final & 26 \\
\hline \multirow{3}{*}{ Total } & Initial & 1476 & \multirow{3}{*}{ Total } & Initial & 3527 \\
\hline & Medial & 403 & & Medial & 1548 \\
\hline & Final & 265 & & Final & 512 \\
\hline
\end{tabular}

\subsection{Experiment Two: Phoneme Monitoring in Kaqchikel and Spanish}

Phoneme monitoring is a well-known task to study phonological processes (Newman \& Dell, 1978; Frauenfelder \& Segui, 1989). Typically, a person has to press a button if a certain phoneme is observed and withhold a response or press a different button if it is not observed. The dependent variables are detection latency and accuracy (errors) with a particular interest on false positives (i.e. phoneme detection where there is none). There are several variants including auditory monitoring (e.g. Cutler, 1976; Cutler \& Otake, 1994), translation tasks (e.g. Wheeldon \& Levelt, 1995) and internal speech generation (for instance triggered by pictorial stimuli).

It is assumed that this task taps into phonological representations of words (Dijkstra, Roelofs, \& Fieuws, 1995; Wheeldon \& Levelt, 1995) and it has been suggested that this task is dependent on syllable identification (Segui, Frauenfelder, \& Mehler, 1981). According to Özdemir, Roelofs \& Levelt (2007) the phoneme-monitoring task essentially uses the same production processes (including the phonological sequential activation) for target phoneme monitoring and is therefore suitable for the purposes of investigating potential right-to-left incrementality in the construction of Kaqchikel phonology.

The experiment was straightforward. Participants were shown pictures and their task was to assess whether a certain phoneme appeared in the name of the object pictured. For instance, when monitoring for the phoneme /s/ in pictures of a scorpion (sina'j; target at initial position) and a doll (ala'ś; target at final position) participants would have to press the "YES" button to indicate the presence of the phoneme /s/, but for flower (kotzij) they would have to press the "NO" button. The same logic was applied to the Spanish version of the task, for instance, for the phoneme /l/ (initial position: libro [book]; final position: árbol [tree]; and a control picture: tomate [tomato]).

Stimuli. For the Kaqchikel language 30 pictures were selected having target phonemes in the first position and 30 pictures having target phonemes in the final position. There were 60 filler pictures which did not have any of the instructed target phonemes in them making up the "no" responses for the task. For Spanish the number of pictures was 26 for each condition with 52 filler items. Stimuli were subdivided into the following phonemes: $/ \mathrm{j} /$, 
/k/, /k’/, and /s/ for Kaqchikel and /d/, /l/, /n/ and /r/ for Spanish. See Appendix A (Kaqchikel) and B (Spanish) for an overview of the stimuli used.

Procedure. Participants were instructed to determine if the particular phoneme was present in the name of the object displayed. Before the practice and experiment proper started, participants received a booklet containing all the pictures and their proper names. First, twelve warm up trials (not used in the experiment) were administered (using the /c/ phoneme for Spanish and /q'/ phoneme for Kaqchikel). When participants could successfully perform this task, the experiment proper would start. The procedure for the practice part and the experiment proper was identical: after receiving instruction (from the experimenter) before the block concerning the phoneme they would be monitoring for, participants were shown a fixation cross $(1000 \mathrm{~ms})$, subsequently a target picture that disappeared from the screen when they made a response, followed by an empty inter trial interval (1000 ms). This procedure was repeated for the whole block. After finishing a block there was a small break and participants were instructed which phoneme they would be monitoring for next. There were four blocks (one phoneme per block), which were counterbalanced. Kaqchikel phoneme monitoring was always presented before Spanish phoneme monitoring (to avoid any bias from Spanish).

Kaqchikel results. During the experiment, we found that 15 participants were unable to accomplish the task mostly due to either the fact that their Kaqchikel language level was too low or due to having particular difficulties remembering the picture names. These participants were excluded leaving 57 participants for subsequent analyses. We removed outliers (all RTs faster than $300 \mathrm{~ms}$ and slower than $3500 \mathrm{~ms}$ comprising $11.3 \%$ of the data) and all errors (10.9\%) leaving $77.8 \%$ of the data available for analysis.

We found that on average participants were $98 \mathrm{~ms}$ (1430 ms initial vs. $1528 \mathrm{~ms}$ final) faster to detect target phonemes at the beginning of words compared to the ending. $t_{1}(56)=3.8, \mathrm{SE}=26.1, p<.001 ; t_{2}(58)=2.4, \mathrm{SE}=$ 38.0, $p<.05$.

Spanish results. We removed outliers (all RTs faster than $300 \mathrm{~ms}$ and slower than $3500 \mathrm{~ms}$ comprising 9.2\% of the data) and all errors (6.9\%) leaving $83.9 \%$ of the data available for analysis. We found that on average participants were $131 \mathrm{~ms}$ (1331 ms initial vs. $1462 \mathrm{~ms}$ final) faster to detect target phonemes at the beginning of words compared to the ending. $t_{1}(56)=5.1, \mathrm{SE}=25.5, p<.001 ; t_{2}(58)=2.3, \mathrm{SE}=49.0, p<.05$.

Discussion. We found no evidence for right-to-left incrementality in Kaqchikel phonological encoding. The pattern between Spanish and Kaqchikel was quite similar and judgments to pictures having the target phoneme in the initial position were always faster compared to when it was in the end position. One particular confound of this experiment, however, may be that the length of the picture names in the end condition was somewhat longer than the beginning condition. A new experiment optimally balancing these conditions for length should clarify whether this was indeed an issue.

\section{General Discussion}

It has been proposed by Nasukawa et al. (2013) that in Kaqchikel the dependency structure and stress assignment patterns are exactly reversed compared to Indo-European languages. This may have important consequences for the way Kaqchikel phonology is encoded. According to the well-known Levelt et al. (1999) model of language production, phonological encoding takes place by incrementally encoding phonemes rightwards into metrical frames. This process, however, may be opposite in Kaqchikel. This paper sought to clarify this issue and performed two experiments (word generation and phoneme monitoring) which are believed to tap into phonological encoding. The results of these experiments are quite clear: no evidence was found for leftward phonological encoding in Kaqchikel. However, there are some factors that may have contributed to this pattern.

The most important factor is that the participants recruited for these experiments may in fact not have been native speakers of Kaqchikel. This can be seen in the number of words generated between Kaqchikel and Spanish in Experiment 1. The number was much greater for Spanish. Subjects seemed to be unbalanced SpanishKaqchikel speakers with much greater proficiency in Spanish. If so, it is assumed that Spanish must be the first language (L1) while Kaqchikel is the second language (L2). As there is no standard test to measure Kaqchikel proficiency, it is unclear what their exact level is. Although one may wonder why simply monolingual Kaqchikel speakers are not recruited, this is quite difficult in Guatemala as Spanish is commonly the first language acquired.

Another important factor is likely to be the influence of Spanish. As Spanish is the most common language spoken in Guatemala, it stands to reason that this is also the language commonly used by the participants. Assuming participants' Kaqchikel proficiency is most like L2, there still might be considerable influence from L1 
Spanish. Non-selective activation of bilingual lexicon is observed in phonological relations (de Groot, Delmaar, \& Lupker, 2000; Dijkstra, Grainger, \& van Heuven, 1999; Jared \& Kroll, 2001; Jared \& Szucs, 2002), orthographic relations (Dijkstra, Timmermans, \& Schriefers, 2000; van Heuven, Dijkstra, \& Grainger, 1998), and even relations of grammatical features (Bordag, Opitz, \& Pechmann, 2006; Salamoura \& Williams, 2007; Lemhöfer, Spalek, \& Schriefers, 2008). In addition, the asymmetry in lexical processing in bilinguals (e.g. Kroll \& Groot, 1997; Kroll \& Stewart, 1994; Kroll \& Tokowicz, 2005; Sholl, Sankaranarayanan, \& Kroll, 1995) expects stronger influence from the forward processing of L1 to L2 than the backward processing from L2 to L1. This influential direction from L1 to L2 lexicon, which is non-selectively activated, could appear as a strong L1 Spanish influence toward L2 Kaqchikel, resulting in the leftward phonological encoding appearing in L2 Kaqchikel as well as L1 Spanish.

Lastly, the possibility exists that the two experiments are not sensitive enough, or else, are not able to tap into the phonological encoding process. In the pursuit of a strictly monostratal model of phonology which abandons the underlying-surface distinction (contrary to the model of language production in Levelt et al. (1999), Nasukawa et al. (2013) omit from phonological representations all precedence (right-to-left/left-to-right) relations between units such as features and syllables. This approach allows the relative ordering of such units to be viewed merely as a by-product of phonetic interpretation, which is controlled by the sensorimotor systems. In this model, the segment, which is usually written as a single alphabetic symbol, does not have any role in expressing contrasts or in shaping phonetic interpretation. For example, in "triangular" theories of melodic representation the vowels [i], [u], [a] are the phonetic interpretation of the three melodic features $|\mathrm{I}|,|\mathrm{U}|$ and $|\mathrm{A}|(\mathrm{Har}-$ ris, 2004; Nasukawa, 2014).

It is clear that there exist two distinct levels which could be sensitive to the experiments we conducted: 1) the headed or non-headed status of a hierarchical structure at the phonological level, and 2) the left/right relations between the individual phonetic sounds in a word when it is pronounced. If the given experiments are sensitive to 2) at the phonetic level, then the results say nothing about phonological encoding: referring to right/left "segment" has nothing to do with phonology; rather, it relates to the phonetic outcome of a phonological structure.

In all, although we are unable to find experimental evidence to corroborate the claims by Nasukawa et al. (2013) there are still many avenues to pursue and future experiments will reveal whether indeed the underlying mechanisms of Kaqchikel phonological encoding follow a reversed pattern or not.

\section{Acknowledgements}

We are grateful to Juan Esteban Ajsivinac Sian, Filiberto Patal Majzul, Lolmay Pedro Oscar García Mátzar and other supporting staff members for their invaluable support for our research in Guatemala. We would also like to thank the research participants. The work for the present article was supported by the Japan Society for the Promotion of Science under Grant-in-Aid for Scientific Research (S) (No. 22222001, Principal Investigator: Masatoshi Koizumi), and Grant-in-Aid for Challenging Exploratory Research (No. 25580112, Principal Investigator: Katsuo Tamaoka).

\section{References}

Anderson, J. M., \& Ewen, C. J. (1987). Principles of Dependency Phonology. Cambridge: Cambridge University Press.

Bordag, D., Opitz, A., \& Pechmann, T. (2006). Gender Processing in L1 and L2: The Role of Noun Termination. Journal of Experimental Psychology: Learning, Memory, and Cognition, 32, 1090-1101.

Charette, M. (1991). Conditions on Phonological Government. Cambridge: Cambridge University Press.

Chen, J.-Y., Chen, T.-M., \& Dell, G. S. (2002). Wordform Encoding in Mandarin Chinese as Assessed by the Implicit Priming Task. Journal of Memory and Language, 46, 751-781.

Cutler, A. (1976). Phoneme-Monitoring as a Function Of Preceding Intonation Contour. Perception and Psychophysics, 20, 55-60.

Cutler, A., \& Otake, T. (1994). Mora or Phoneme? Further Evidence for Language-Specific Listening. Journal of Memory and Language, 33, 824-844.

De Groot, A. M. B., Delmaar, P., \& Lupker, S. J. (2000). The Processing of Interlexical Homographs in Translation Recognition and Lexical Decision: Support for Non-Selective Access to Bilingual Memory. Quarterly Journal of Experimental Psychology: Human Experimental Psychology, 53A, 397-428.

Dijkstra, T., Grainger, J., \& Van Heuven, W. J. B. (1999). Recognition of Cognates and Interlingual Homographs: The Neg- 
lected Role of Phonology. Journal of Memory and Language, 41, 496-518.

Dijkstra, T., Roelofs, A. \& Fieuws, S. (1995). Orthographic Effects on Phoneme Monitoring. Canadian Journal of Experimental Psychology, 49, 264-271.

Dijkstra, T., Timmermans, M., \& Schriefers, H. (2000). On Being Blinded by Your Other Language: Effects of Task Demands on Interlingual Homograph Recognition. Journal of Memory and Language, 42, 445-464.

Frauenfelder, U. H., \& Segui, J. (1989). Phoneme Monitoring and Lexical Processing: Evidence for Associative Context Effects. Memory and Cognition, 17, 134-140. http://dx.doi.org/10.3758/BF03197063

Harris, J. (1994). English Sound Structure. Oxford: Basil Blackwell.

Harris, J. (1997). Licensing Inheritance: An Integrated Theory of Neutralisation. Phonology, 14, 315-370. http://dx.doi.org/10.1017/S0952675798003479

Harris, J. (2004). Release the Captive Coda: The Foot as a Domain of Phonetic Interpretation. In J. K. Local, R. Ogden, \& R. A. M. Temple (Eds.), Phonetic Interpretation (pp. 103-129). Cambridge: Cambridge University Press.

Harris, J., \& Gussmann, E. (1998). Final Codas: Why the West Was Wrong. In E. Cyran (Ed.), Structure and Interpretation: Studies in Phonology (pp. 139-162). Lublin: Folium.

Harris, J., \& Gussmann, E. (2002). Word-Final Onsets. UCL Working Papers in Linguistics, 14, 1-42.

Jared, D., \& Kroll, J. F. (2001). Do Bilinguals Activate Phonological Representations in One or Both of Their Languages When Naming Words? Journal of Memory and Language, 44, 2-31. http://dx.doi.org/10.1006/jmla.2000.2747

Jared, D., \& Szucs, C. (2002). Phonological Activation in Bilinguals: Evidence from Interlingual Homograph Naming. Bilingualism: Language and Cognition, 5, 225-239. http://dx.doi.org/10.1017/S1366728902003024

Kaye, J. D. (1990). “Coda” Licensing. Phonology, 7, 301-330. http://dx.doi.org/10.1017/S0952675700001214

Kaye, J. D., Lowenstamm, J., \& Vergnaud, J.-R. (1990). Constituent Structure and Government in Phonology. Phonology, 7, 193-232. http://dx.doi.org/10.1017/S0952675700001184

Kroll, J. F., \& de Groot, A. M. B. (1997). Lexical and Conceptual Memory in the Bilingual: Mapping Form to Meaning in Two Languages. In A. M. B. De Groot, \& J. F. Kroll (Eds.), Tutorials in Bilingualism: Psycholinguistic Perspectives (pp. 169-199). Mahwah, NJ: Lawrence Erlbaum Publishers.

Kroll, J. F., \& Stewart, E. (1994). Category Interference in Translation and Picture Naming: Evidence for Asymmetric Connections between Bilingual Memory Representations. Journal of Memory and Language, 33, 149-174. http://dx.doi.org/10.1006/jmla.1994.1008

Kroll, J. F., \& Tokowicz, N. (2005). Models of Bilingual Representation and Processing: Looking Back and to the Future. In J. F. Kroll, \& A. M. B. de Groot (Eds.), Handbook of Bilingualism: Psycholinguistic Approaches (pp. 531-553). New York: Oxford University Press.

Kureta, Y., Fushimi, T., \& Tatsumi, I. F. (2006). The Functional Unit of Phonological Encoding: Evidence for Moraic Representation in Native Japanese Speakers. Journal of Experimental Psychology: Learning, Memory, and Cognition, 32, 1102-1119. http://dx.doi.org/10.1037/0278-7393.32.5.1102

Lemhöfer, K., Spalek, K., \& Schriefers, H. (2008). Cross-Language Effects of Grammatical Gender in Bilingual Word Recognition and Production. Journal of Memory and Language, 59, 312-330. http://dx.doi.org/10.1016/j.jml.2008.06.005

Levelt, W. J. M., Roelofs, A., \& Meyer, A. S. (1999). A Theory of Lexical Access in Speech Production. Behavioral and Brain Sciences, 22, 1-75. http://dx.doi.org/10.1017/S0140525X99001776

Meyer, A. S. (1990). The Time Course of Phonological Encoding in Language Production: The Encoding of Successive Syllables of a Word. Journal of Memory and Language, 29, 524-545. http://dx.doi.org/10.1016/0749-596X(90)90050-A

Meyer, A. S. (1991). The Time Course of Phonological Encoding in Language Production: Phonological Encoding inside a Syllable. Journal of Memory and Language, 30, 69-89. http://dx.doi.org/10.1016/0749-596X(91)90011-8

Nasukawa, K. (1998). Prosodic Integrity and Melodic Representation in Nasals. Interdisciplinary Information Sciences, 4, 1-8. http://dx.doi.org/10.4036/iis.1998.1

Nasukawa, K. (2004). Word-Final Consonants: Arguments against a Coda Analysis. Proceedings of the 58th Conference, Tohoku English Literary Society, 47-53.

Nasukawa, K. (2011). Representing Phonology without Precedence Relations. English Linguistics, 28, 278-300. http://dx.doi.org/10.9793/elsj.28.2_278

Nasukawa, K. (2014). Features and Recursive Structure. Nordlyd, 41, 1-19.

Nasukawa, K., Yasugi, Y., \& Koizumi, M. (2013). Syllable Structure and the Head Parameter in Kaqchikel. In M. Kenstowicz (Ed.), Studies in Kaqchikel Grammar (pp. 81-95). MIT Working Papers in Linguistics, Cambridge, MA: Massachusetts Institute of Technology.

Newman, J. E., \& Dell, G. S. (1978). The Phonological Nature of Phoneme Monitoring: A Critique of Some Ambiguity Stu- 
dies. Journal of Verbal Learning and Verbal Behavior, 17, 359-374. http://dx.doi.org/10.1016/S0022-5371(78)90228-1

Özdemir, R., Roelofs, A., \& Levelt, W. J. M. (2007). Perceptual Uniqueness Point Effects in Monitoring Internal Speech. Cognition, 105, 457-465. http://dx.doi.org/10.1016/j.cognition.2006.10.006

Roelofs, A. (1996). Serial Order in Planning the Production of Successive Morphemes of a Word. Journal of Memory and Language, 35, 854-876. http://dx.doi.org/10.1006/jmla.1996.0044

Roelofs, A. (2008). Tracing Attention and the Activation Flow in Spoken Word Planning Using Eye Movements. Journal of Experimental Psychology: Learning, Memory, and Cognition, 34, 353-368. http://dx.doi.org/10.1037/0278-7393.34.2.353

Roelofs, A. (2015). Modeling of Phonological Encoding in Spoken Word Production: From Germanic Languages to Mandarin Chinese and Japanese. Japanese Psychological Research, 57, 22-37. http://dx.doi.org/10.1111/jpr.12050

Salamoura, A., \& Williams, J. N. (2007). The Representation of Grammatical Gender in the Bilingual Lexicon: Evidence from Greek and German. Bilingualism: Language and Cognition, 10, 257-275. http://dx.doi.org/10.1017/S1366728907003069

Segui, J., Frauenfelder, U., \& Mehler, J. (1981). Phoneme Monitoring, Syllable Monitoring and Lexical Access. British Journal of Psychology, 72, 471-477. http://dx.doi.org/10.1111/j.2044-8295.1981.tb01776.x

Sholl, A., Sankaranarayanan, A., \& Kroll, J. F. (1995). Transfer between Picture Naming and Translation: A Test of Asymmetries in Bilingual Memory. Psychological Science, 6, 45-49. http://dx.doi.org/10.1111/j.1467-9280.1995.tb00303.x

Van der Hulst, H. (1995). Radical CV Phonology: The Categorial Gesture. In J. Durand, \& F. Katamba (Eds.), Frontiers of Phonology: Atoms, Structures, Derivations (pp. 80-116). Harlow, Essex: Longman.

Van Heuven, J. B., Dijkstra, T., \& Grainger, J. (1998). Orthographic Neighborhood Effects in Bilingual Word Recognition. Journal of Memory and Language, 39, 458-483. http://dx.doi.org/10.1006/jmla.1998.2584

Wheeldon, L. R., \& Levelt, W. J. M. (1995) Monitoring the Time Course of Phonological Encoding. Journal of Memory and Language, 34, 311-334. http://dx.doi.org/10.1006/jmla.1995.1014 
Appendix A. Overview of the Kaqchikel Stimuli Used in Experiment 2

\begin{tabular}{|c|c|c|c|c|}
\hline & Beginning & Ending & Neutral & Neutral \\
\hline \multirow{8}{*}{$/ \mathrm{k} /$} & kär (fish) & chak (grain) & q'aq' (fire) & jolomaj (head) \\
\hline & kej (horse) & k'ulub'ïk (wedding) & ayin (alligator) & ab' (hamak) \\
\hline & ka'aj (hut) & mama'äk (rooster) & oköx (mushroom) & wäy (mytortilla) \\
\hline & kaj (sky) & raxik (long chili pepper) & q'ab'aj (arm ) & alanxäx (orange) \\
\hline & kamxa (shirt) & ch'ök (greckle) & q'ij (sun) & Alaxel (baby) \\
\hline & kape (coffee) & sanik (ant) & ach'i'y (slingshot) & amoroy (beetle) \\
\hline & kaplin (cherry) & tz'ik (elbow) & top (crab) & B'ajib’äl (hammer) \\
\hline & karne'l (sheep) & pek (cave) & aq'awinäq (raccoon) & B’aq jolom (skeleton) \\
\hline \multirow{6}{*}{$/ k^{\prime} /$} & k'oy (monkey) & sik' (cigar) & kaqaq'oq' (watermelon) & nimach'oy (rat) \\
\hline & k'um (pumpkin) & ajsik' (smoker) & tukr (owl) & b'aq (syringe) \\
\hline & k'äq (flea) & äk' (hen) & wakx (cow) & ajlab'al (soldier) \\
\hline & k'ix (chayote) & kisik' (goat) & xene' (mosquito) & b'o'j (cotton) \\
\hline & k'an (rope, cord) & IXTOLOK' (lizard) & xkoya' (tomato) & ajq'ij (mayanpriest) \\
\hline & k'ixawuch' (porcupine) & sak' (locust) & xnakät (onion) & bojo'y (pot) \\
\hline \multirow{6}{*}{$/ \mathrm{s} /$} & saqmolo' (egg) & tra's (peach) & xab'on (soap) & kelonel (painter) \\
\hline & saq'ul (banana) & mich'q'ös (grass) & tolob'an (boaconstrictor ) & k'oj (mask) \\
\hline & saqwäch (potato) & ïs (bodyhair) & tix (elephant) & kotz'I'j (flower) \\
\hline & sina'j (scorpion) & mes (garbage) & b'ojo'y (pot) & Ch’a' (arrow) \\
\hline & sotz' (bat) & ala's (doll) & k'u'x (nest) & chom (shrimp) \\
\hline & saqb'in (weasel) & peqäs (backpack) & ichaj (herbs) & ch'oxch'ïk (knot) \\
\hline \multirow{10}{*}{$/ \mathrm{j} /$} & jaqb'äl (key) & rupaläj (face) & ayüm (yawn) & kaxlan mixku' (apple) \\
\hline & jay (house) & tzamaj (nose) & am (spider) & tuktuk (woodpecker) \\
\hline & jöj (crow) & xikinaj (ear) & anx (garlic) & aq (pig) \\
\hline & jey (tail) & xik'aj (wings) & atinib'äl (bathtub) & kaqix (macaw) \\
\hline & jicha'n (comb) & sokaj (nest) & b'alam (jaguar) & inay (iguana) \\
\hline & jo'q (cornhusk) & aqanaj (foot) & xpeq (toad) & ixkanul (volcano) \\
\hline & jäb' (rain) & aq'aj (tongue) & chakäch (basket) & xiwak (conch) \\
\hline & juku' (canoe) & ch'ekaj (knee) & ch'atal (table) & xi'l (cricket) \\
\hline & jut (worm) & chaj (ash) & ch'op (pineapple) & masat (deer) \\
\hline & jul (hole) & eyaj (tooth) & manq'uq' (quetzal) & k'isis (cypress) \\
\hline
\end{tabular}


Appendix B. Overview of the Spanish Stimuli Used in Experiment 2

\begin{tabular}{|c|c|c|c|c|}
\hline & Beginning & Ending & Neutral & Neutral \\
\hline \multirow{8}{*}{$/ 1 /$} & lago (lake) & caracol (seasnail) & casa (house) & fuego (fire) \\
\hline & leche (milk) & carrusel (carrousel) & arete (earring) & hongo (mushroom) \\
\hline & león (lion) & árbol (mytree) & aeropuerto (airport) & bostezo (yawn) \\
\hline & libro (book) & canal (canal) & agua (water) & cangrejo (crab) \\
\hline & línea (line) & cárcel (jail) & naranja (orange) & mapache (raccoon) \\
\hline & langosta (lobster) & sol (sun) & calendario (calendar) & sandia (watermelon) \\
\hline & luna (moon) & miel (honey) & camino (road) & tomate (mytomato) \\
\hline & lanza (spear) & futbol (soccer) & campo (field) & jabon (soap) \\
\hline \multirow{6}{*}{$/ \mathrm{n} /$} & nudo (knot) & avión (airplane) & cerro (hill) & caballo (horse) \\
\hline & nido (nest) & camión (mytruck) & cielo (sky) & cebolla (onion) \\
\hline & nave spacial (spaceship) & corazón (heart) & cuadro (picture) & buho (owl) \\
\hline & niña (girl) & pan (bread) & cuarto (room) & vaca (cow) \\
\hline & niño (boy) & televisión (mytelevision) & bosque (forest) & sapo (toad) \\
\hline & nebrina (fog) & tren (train) & bus (bus) & bebe (baby) \\
\hline \multirow{6}{*}{$/ \mathrm{r} /$} & rata (rat) & bailador (dancer) & ganado (cattle) & elefante (elephant) \\
\hline & radio (radio) & pescador (fisherman) & gato (cat) & manzana (apple) \\
\hline & raíz (root) & flor (flower) & honda (slingshot) & ajo (garlic) \\
\hline & rama (branch) & mar (sea) & iguana (iguana) & mesa (mytable) \\
\hline & ramo (flowerbouquet) & motor (engine) & alimento (food) & pina (pineapple) \\
\hline & río (river) & mujer (woman) & mano (hand) & quetzal (quetzal) \\
\hline \multirow{6}{*}{$/ \mathrm{d} /$} & diablo (devil) & ataud (coffin) & cámara (camera) & hamaca (hamak) \\
\hline & durazno (peach) & esclavitud (slavery) & flecha (arrow) & martillo (hammer) \\
\hline & diamante (diamond) & juventud (youth) & сора (cup) & arana (spider) \\
\hline & dinero (money) & pared (wall) & ronron (beetle) & silla (chair) \\
\hline & disco (disk) & sed (mythirsty) & uva (coin) & tortilla (mytortilla) \\
\hline & doctor (doctor) & red (mynet) & iglesia (church) & mascara (mask) \\
\hline
\end{tabular}

